\title{
Impact of systemic anticancer therapy in pediatric optic pathway glioma on visual function: a systematic review.
}

\author{
Carlien Bennebroek ${ }^{1}$, Laura Wijninga ${ }^{2}$, Jaqueline Limpens ${ }^{1}$, Antoinette Schouten-van \\ Meeteren $^{3}$, and Peerooz Saeed ${ }^{1}$ \\ ${ }^{1}$ Amsterdam UMC Locatie AMC \\ ${ }^{2}$ University of Amsterdam \\ ${ }^{3}$ Princess Máxima Center for Pediatric Oncology
}

March 9, 2021

\begin{abstract}
Abstract: Background: Systemic anticancer therapy (SAT) is the standard treatment for unresectable (progressive) pediatric optic pathway glioma (OPG), which can seriously affect visual function. New SAT modalities have been introduced the last decennium. Methods: MEDLINE and EMBASE (Ovid) were searched for studies reporting on change in visual acuity and visual field after start of treatment with SAT for OPG (1990-August 2020). Results: In 11 studies including 358 patients improvement of binocular VA was found in $0-45 \%$, stability in $18-77 \%$ and decrease in $0-82 \%$ of patients. Considerable heterogeneity among included studies made a meta-analysis not appropriate. Studies on VEGF and MAPK signaling inhibition did not meet the eligibility criteria. Conclusion. This systematic review suggests a positive impact of SAT on pediatric OPG. However, the wide ranges reported in efficacy of SAT and the observed heterogeneity highlight the need for prospective studies with uniform definitions.
\end{abstract}

\section{Hosted file}

Systematic review OPG SAS and visual function-PBC-08032021.pdf available at https: //authorea.com/users/400517/articles/512836-impact-of-systemic-anticancer-therapy-inpediatric-optic-pathway-glioma-on-visual-function-a-systematic-review

\section{Hosted file}

TABLE 1- SAT OPG SR-PBC-08032021.pdf available at https://authorea.com/users/400517/articles/ 512836-impact-of-systemic-anticancer-therapy-in-pediatric-optic-pathway-glioma-onvisual-function-a-systematic-review

\section{Hosted file}

TABLE 2-SAT OPG SR-PBC-08032021.pdf available at https://authorea.com/users/400517/articles/ 512836-impact-of-systemic-anticancer-therapy-in-pediatric-optic-pathway-glioma-onvisual-function-a-systematic-review

\section{Hosted file}

TABLE 3-SAT OPG SR-PBC-08032021.pdf available at https://authorea.com/users/400517/articles/ 512836-impact-of-systemic-anticancer-therapy-in-pediatric-optic-pathway-glioma-onvisual-function-a-systematic-review 
FIGURE 1: PRISMA flow chart showing selection of articles for systematic review.

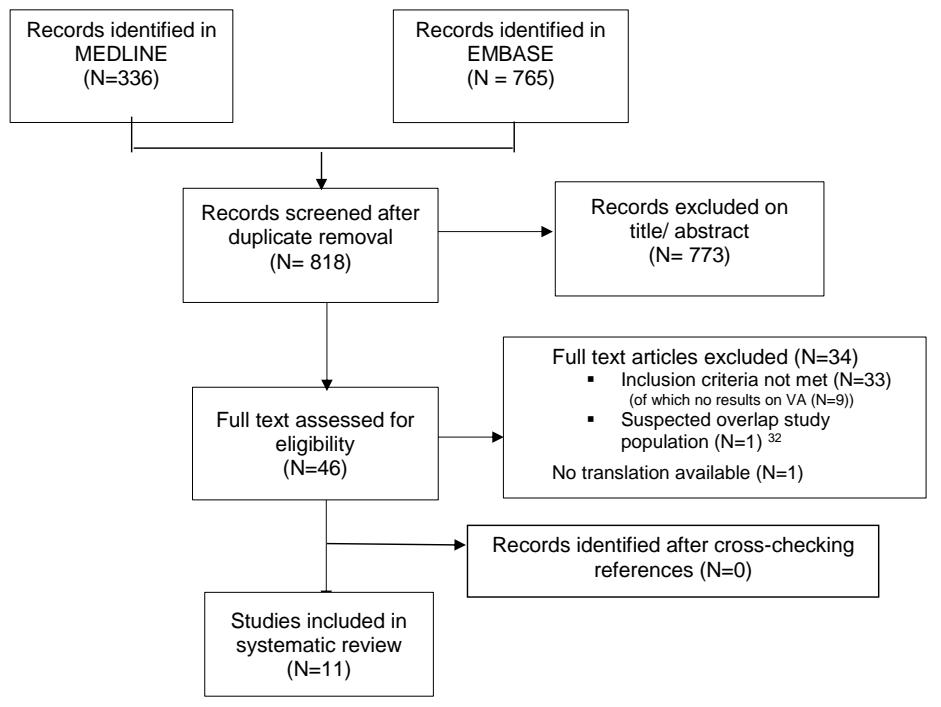

